\title{
Variation in osmoregulation in differentially drought-sensitive wheat genotypes involves calcium
}

\author{
H. NAYYAR \\ Department of Botany, Panjab University, Chandigarh-160014, India
}

\begin{abstract}
Two wheat (Triticum aestivum L.) genotypes differing in their sensitivity to water deficit (stress tolerant - C306 and stress susceptible - HD2329) were subjected to osmotic stress for $7 \mathrm{~d}$ using polyethylene glycol (PEG-6000; osmotic potential $-1.0 \mathrm{MPa})$, at initial vegetative growth. The plants were either supplemented with $1 \mathrm{mM} \mathrm{CaCl}\left(\mathrm{Ca}^{2+}\right)$ alone or along with verapamil (VP; calcium channel blocker) to investigate the involvement of calcium in governing osmoregulation. Relative elongation rate (RER), dry matter (DM) production, water potential $\left(\psi_{w}\right)$, electrolyte leakage (EL), contents of proline (Pro) and glycine betaine (GB) and activities of $\gamma$-glutamyl kinase (GK) and proline oxidase (PO) in shoots and roots were examined during stress period. C306 showed relatively higher accumulation of Pro while HD2329 accumulated more GB under stress. RER, DM and $\psi_{\mathrm{w}}$ were relatively higher in C306 than HD2329. Roots compared to shoots showed lower content of osmolytes but had faster rate of their accumulation. Presence of $\mathrm{Ca}^{2+}$ in the medium increased the activity of GK and decreased that of $\mathrm{PO}$ while in the presence of its inhibitor, decrease in activity of both the enzymes was observed. $\mathrm{Ca}^{2+}$ appeared to reduce the damaging effect of stress by elevating the content of Pro and $\mathrm{GB}$, improving the water status and growth of seedlings and minimizing the injury to membranes. The protective effect of $\mathrm{Ca}^{2+}$ was observed to be more in HD2329 than C306.
\end{abstract}

Additional key words: glycine betaine, $\gamma$-glutamyl kinase, proline, proline oxidase, Triticum aestivum, verapamil.

\section{Introduction}

Osmoregulation is a stress-related adaptive mechanism that imparts protection to dehydrating tissues (Morgan 1992). Proline (Pro) and glycine betaine (GB) are two such solutes implicated in osmoregulation of plants in response to stresses causing dehydration (Delauney and Verma 1993, Rhodes and Hanson 1993, Hare and Cress 1997). These solutes offer protection at multiple levels in cells (Huang et al. 2000) and have been currently the target of genetic engineering to increase stress tolerance in plants (McNeil et al. 1999, Rathinasabapathi 2000, deRonde et al. 2000). For example, Pro synthesis is implicated as a mechanism of alleviating cytoplasmic acidosis, and may maintain suitable $\mathrm{NADP}^{+} / \mathrm{NADPH}$ ratios (Hare and Cress 1997). GB has been shown to stabilize enzymes and membranes (Krall et al. 1989, Zhao et al. 1992). and the photosystem 2 protein-pigment complex during stress (Murata et al. 1992, Papageorgiou and Murarata 1995). The regulation of these osmoprotectants is not well understood and has been the subject of some recent studies (Yoshiba et al. 1997, Trotel-Aziz et al. 2000, Yang et al. 2000). The information on nature of signal transduction pathway linking the perception of the osmotic stress and Pro accumulation is limited (Hare et al. 1999). Calcium plays an essential role in stress signaling (Knight et al. 1997) and in stress protection (Arazi et al. 1999, Knight and Knight 2001). Stress induced Pro accumulation has been proposed to be linked with cytosolic calcium (Knight et al. 1997). The present study was, therefore, planned to investigate the participation of calcium $\left(\mathrm{Ca}^{2+}\right)$ in governing the accumulation of Pro and GB, the two major osmolytes in wheat genotypes differing in stress sensitivity. It was hypothesized that genotypes varying in stress sensitivity might differ with respect to type, amount and rate of accumulation of osmolytes in roots and shoots and calcium may be a key factor governing the osmoregulation during stress conditions.

Received 5 November 2002, accepted 7 February 2003.

Abbreviations: DM - dry matter; EL - electrolyte leakage; GB - glycine betaine; GK - $\gamma$-glutamyl kinase; PEG - polyethylene glycol; PO - proline oxidase; RER - relative elongation rate; VP - verapamil.

E-mail: nayyarbot@pu.ac.in 


\section{Materials and methods}

Two wheat (Triticum aestivum L.) genotypes, C306 (tolerant type) and HD2329 (susceptible type) were grown in growth chamber (SEW, New Delhi, India; temperature: $23 / 20{ }^{\circ} \mathrm{C} ; 16-\mathrm{h}$ photoperiod; irradiance $250 \mu \mathrm{mol} \mathrm{m} \mathrm{m}^{-2} \mathrm{~s}^{-1}$ ). The water stress was applied to 15-d-old seedlings by incorporating polyethylene glycol 6000 (PEG; - 1.0 MPa) in the growth medium. Simultaneously calcium chloride $(1 \mathrm{mM})$ or calcium channel blocker, verapamil $(0.5 \mathrm{mM})$ were added in the medium. The concentrations opted for PEG, calcium chloride and verapamil were evaluated in a preliminary experiment on the basis of their effect on growth and electrolyte leakage. The plants were investigated for their growth, proline and its metabolic enzymes, glycine betaine since the beginning of stress till the end of it at $7^{\text {th }}$ day. The data are presented for $1^{\text {st }}$ and $7^{\text {th }}$ day.

The proline content was estimated by the method of Bates et al. (1973). The plant material was homogenised in $3 \%$ aqueous sulfosalicylic acid and the homogenate was centrifuged at $24000 \mathrm{~g}$. Supernatant was used for estimation of proline content. The reaction mixture consisted of $2 \mathrm{~cm}^{3}$ supernatant, $2 \mathrm{~cm}^{3}$ acid ninhydrin and $2 \mathrm{~cm}^{3}$ of glacial acetic acid, which was boiled at $100^{\circ} \mathrm{C}$ for $1 \mathrm{~h}$. After termination of reaction in ice bath, the reaction mixture was extracted with $4 \mathrm{~cm}^{3}$ of toluene and the absorbance was read at $520 \mathrm{~nm}$ in a UV-visible spectrophotometer (Chemito, New Delhi, India). The amount of glycine betaine was estimated according to method of Grieve and Grattan (1983). The dried plant material was finely ground, mechanically shaken with $20 \mathrm{~cm}^{3}$ deionised water for $24 \mathrm{~h}$ at $25^{\circ} \mathrm{C}$. The samples were then filtered and filtrates were diluted $1: 1$ with $2 \mathrm{M}$ $\mathrm{H}_{2} \mathrm{SO}_{4}$. Aliquots were kept in centrifuge tubes and cooled in ice water for $1 \mathrm{~h}$. Cold $\mathrm{KI}-\mathrm{I}_{2}$ reagent was added and the reactants were gently stirred with a Vortex mixer (Yorco, New Delhi, India). The tubes were stored at $4{ }^{\circ} \mathrm{C}$ for $16 \mathrm{~h}$ and then centrifuged at $24000 \mathrm{~g}$ for $15 \mathrm{~min}$ at $0^{\circ} \mathrm{C}$. The supernatant was carefully aspirated with a fine glass tube. The periodide crystals were dissolved in $9 \mathrm{~cm}^{3}$ of 1.2-dichloroethane. After $2 \mathrm{~h}$, the absorbance was measured at $365 \mathrm{~nm}$ using glycine betaine as standard.

The activity of $\gamma$-glutamyl kinase (ATP: L-glutamate 5-phosphotransferase) was assayed by the method of Hayzer and Leisinger (1980). $1 \mathrm{~g}$ of plant tissue was extracted with $10 \mathrm{~cm}^{3}$ of $50 \mathrm{mM}$ Tris- $\mathrm{HCl}$ buffer ( $\mathrm{pH} \mathrm{7.2)}$ and centrifuged at $24000 \mathrm{~g}$ for $20 \mathrm{~min}$, washed again with $50 \mathrm{mM}$ of Tris- $\mathrm{HCl}$ buffer $(\mathrm{pH} \mathrm{7.2)}$ and stored at freezing temperature. The frozen sample was suspended in $7 \mathrm{~cm}^{3}$ of $50 \mathrm{mM}$ Tris- $\mathrm{HCl}$ buffer containing $1 \mathrm{mM}$ 1,4-dithiothreitol (DTT). The crude extract after desalting was used for determination of enzyme activity. The enzyme assay mixture contained, in a final volume of
$0.25 \mathrm{~cm}^{3}, 50 \mathrm{mM}$ L-glutamate, $10 \mathrm{mM} \mathrm{ATP,} 20 \mathrm{mM}$ $\mathrm{MgCl}_{2}, 100 \mathrm{mM}$ hydroxylamine $\mathrm{HCl}$, and $50 \mathrm{mM}$ Tris base adjusted to $\mathrm{pH} 7.0$ with $0.199 \mathrm{~cm}^{3}$ of enzyme extract containing $3.0 \mathrm{mg}$ enzyme protein in a final volume of $2 \mathrm{~cm}^{3}$. The reaction was started by addition of enzyme extract. After $30 \mathrm{~min}$ of incubation at $37^{\circ} \mathrm{C}$, the reaction was stopped by the addition of $1.0 \mathrm{~cm}^{3}$ of solution containing $\mathrm{FeCl}_{2} .3 \mathrm{H}_{2} \mathrm{O}(2.5 \%, \mathrm{~m} / \mathrm{v})$ and TCA $(6 \% \mathrm{~m} / \mathrm{v})$ in $2.5 \mathrm{M} \mathrm{HCl}$. Precipitated protein was removed by centrifugation at $24000 \mathrm{~g}$ at $0{ }^{\circ} \mathrm{C}$ and absorbance was measured at $535 \mathrm{~nm}$ against water as blank. One unit of enzyme activity was defined as $\mu \mathrm{g}$ of $\gamma$-glutamylhydroxamate formed per min per $\mathrm{mg}$ per protein. $\gamma$-glutamylhydroxamate was used as standard. The activity of proline oxidase was determined according to the method of Huang and Cavalieri (1979). $1 \mathrm{~g}$ of plant tissue was homogenized with $5 \mathrm{~cm}^{3}$ of medium in a pre-chilled mortar and pestle, then filtered through several layers of muslin cloth. The filtrate was centrifuged at $24000 \mathrm{~g}$ for $10 \mathrm{~min}$ in a refrigerated centrifuge at $4{ }^{\circ} \mathrm{C}$. The supernatant was re-centrifuged at $60000 \mathrm{~g}$ for $25 \mathrm{~min}$. The pellet thus obtained was mixed with $1 \mathrm{~cm}^{3}$ Tricine-KOH buffer ( $\mathrm{pH} 7.5$ ) containing $6 \mathrm{M}$ sucrose. This extract was used for assaying the enzyme activity. The extraction was carried out at $4{ }^{\circ} \mathrm{C} .3 \mathrm{~cm}^{3}$ of assay mixture contained $1.2 \mathrm{~cm}^{3}$ of $50 \mathrm{mM}$ Tris- $\mathrm{HCl}$ buffer $(\mathrm{pH} 8.5), 1.2 \mathrm{~cm}^{3}$ of $5 \mathrm{mM} \mathrm{MgCl}_{2}, 0.1 \mathrm{~cm}^{3}$ of $0.5 \mathrm{mM}$ NADP, $0.1 \mathrm{~cm}^{3}$ of $1 \mathrm{mM} \mathrm{KCN}, 0.1 \mathrm{~cm}^{3}$ of $1 \mathrm{mM}$ PMS, $0.1 \mathrm{~cm}^{3}$ of $0.06 \mathrm{mM}$ 2,6-dichlorophenol indophenol (DCPIP) and $0.2 \mathrm{~cm}^{3}$ of $0.1 \mathrm{M}$ proline. The reaction was monitored at $600 \mathrm{~nm}$ at $25^{\circ} \mathrm{C}$ using proline to initiate the reaction. The increase in absorbance was recorded. The rate of reduction of DCPIP was used to determine the enzyme activity expressed as mmol(DCPIP reduced) $\mathrm{mg}^{-1}$ (protein) $\mathrm{min}^{-1}$.

The water potential $\left(\Psi_{w}\right)$ of the shoots was measured with pressure chamber ( $P M S$, Corvallis, USA) at 10:00. The electrolyte leakage (EL) was measured as described by Lutts et al. (1996) using young leaf discs of five plants for each treatment. Samples were washed thrice with deionised water to remove surface adhered electrolytes. Leaf discs were placed in closed vials containing $10 \mathrm{~cm}^{3}$ of deionised water and incubated at $25^{\circ} \mathrm{C}$ on a rotary shaker for $24 \mathrm{~h}$ and subsequently electrical conductivity of the solution $\left(\mathrm{L}_{1}\right)$ was determined using conductivity meter (ELICO, Chandigarh, India). Samples were then autoclaved at $120^{\circ} \mathrm{C}$ for $20 \mathrm{~min}$ and the final electrical conductivity $\left(\mathrm{L}_{2}\right)$ was obtained after equilibration at $25^{\circ} \mathrm{C}$. The EL was defined as: $\mathrm{EL}[\%]=\left(\mathrm{L}_{1} / \mathrm{L}_{2}\right) \times 100$. Relative elongation rate (RER) and dry matter (DM) accumulation were calculated by observing length [ $\mathrm{mm}]$ and dry mass [mg] at interval of $6 \mathrm{~d}$. Statistical analysis was done using Microstat software. 


\section{Results}

Due to stress, proline (Pro) and glycine betaine (GB) content increased by 2 times over the control in shoots and roots of both the genotypes (Fig. 1). The two genotypes showed variation with respect to accumulation of osmolytes. While C306 had relatively higher amount of Pro in its shoots and roots, HD2329 showed higher accumulation of GB. The shoots had higher accumulation of both the osmolytes than roots but their rate of accumulation was higher in latter. The activity of $\gamma$-glutamyl kinase (GK) increased more than twice during stress and shoots had higher activity than roots (Fig. 2) while proline oxidase (PO) activity decreased (Fig. 2) under stress and the decrease was more in roots relative to shoots. The activities of $\mathrm{GK}$ and $\mathrm{PO}$ were also comparatively higher in C306. The damage to membranes due to stress as indicated from electrolyte leakage (EL) was relatively more in shoots than roots (Fig. 3). Water potential decreased due to stress and to a significantly higher extent in HD2329 (Fig. 3). The roots of both the genotypes showed higher growth than shoots during stress. (Fig. 4). C306 showed less reduction in growth of roots and shoots than HD2329, observed as relative elongation rate (RER) and dry matter accumulation (Fig. 4). $\mathrm{Ca}^{2+}$ application in the medium to the stressed plants significantly increased the accumulation of Pro and GB over untreated-stressed plants (Fig. 1). The activity of GK increased significantly while that of $\mathrm{PO}$ decreased slightly in $\mathrm{Ca}^{2 t}$ treated plants (Fig. 2). A significant decrease in EL and increase in $\psi_{w}$ (Fig. 3), RER and DM accumulation (Fig. 4) was noticeable in $\mathrm{Ca}^{2+}$ treated plants. The roots showed higher growth than shoots in presence of $\mathrm{Ca}^{2+}$. A difference in response of two genotypes towards $\mathrm{Ca}^{2+}$ was observed under stress conditions and HD2329 appeared to be more responsive to $\mathrm{Ca}^{2+}$ application as compared to $\mathrm{C} 306$. The former genotype showed relatively higher Pro, $\psi_{w}$, RER and $\mathrm{DM}$ in its roots and shoots in the presence of $\mathrm{Ca}^{2}$ than the latter. The ameliorative effect of calcium could be partially reversed with addition of verapamil $\left(\mathrm{Ca}^{2}\right.$ channel blocker) in $\mathrm{Ca}^{2+}$ containing medium. A significant decrease in Pro and its associated enzymes, $\psi_{w}$, membrane integrity (as EL) and growth was noticed with verapamil over untreated and $\mathrm{Ca}^{2+}$-treated plants, corroborating $\mathrm{Ca}^{2+}$ involvement in these responses.

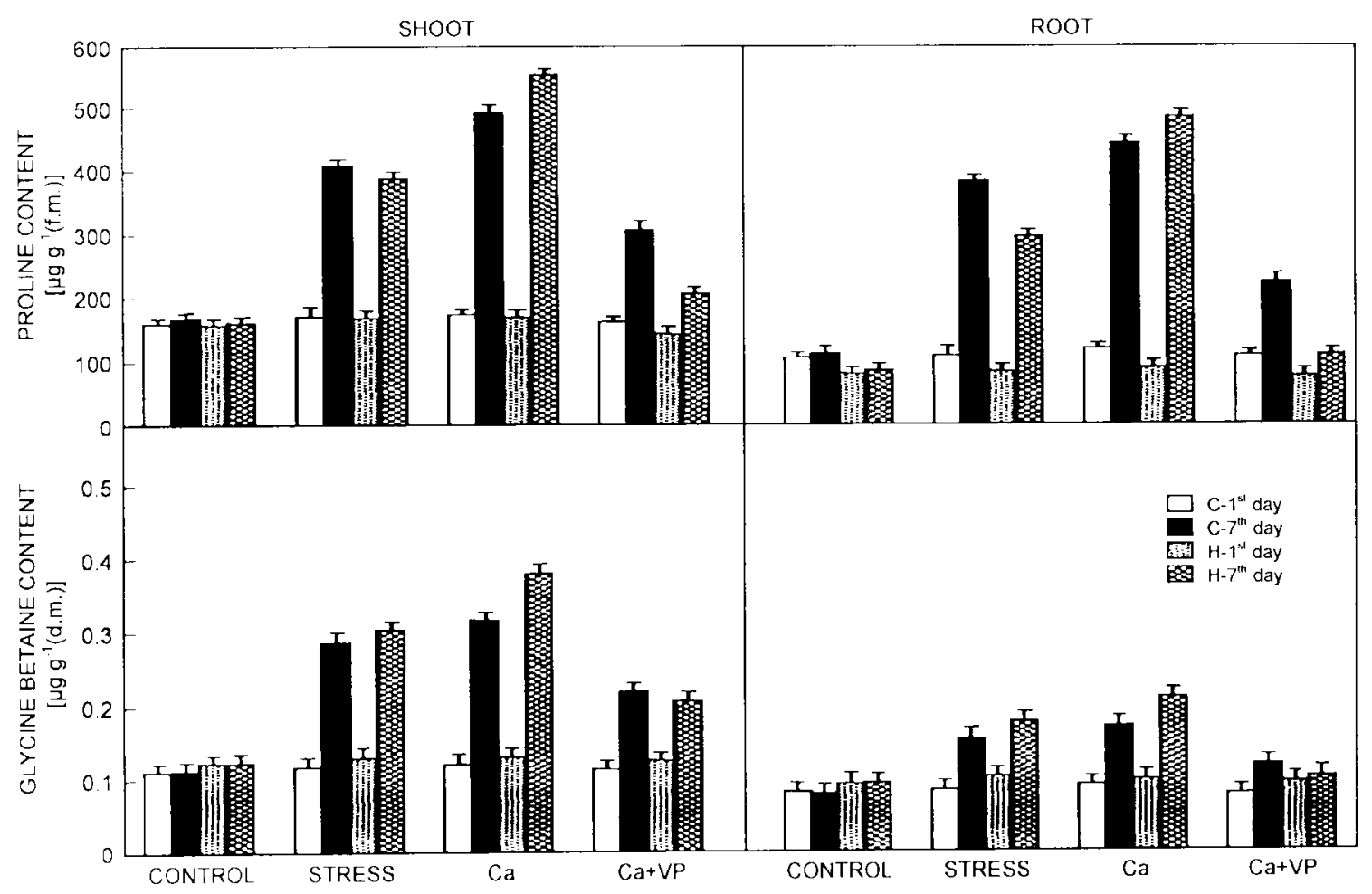

Fig. 1. Effect of water stress, $1 \mathrm{mM}$ calcium chloride (Ca) and $0.5 \mathrm{mM}$ calcium channel blocker verapamil (VP) on proline and glycine beatine content in shoots and roots at $1^{\text {st }}$ and $7^{\text {th }}$ day of stress in C306 (C) and HD2329 (H) wheat genotypes. 15-d-old plants were subjected to PEG-6000 of $-1.0 \mathrm{MPa}$ for $7 \mathrm{~d}$ and the observations were recorded during stress period. Means \pm SE of three different samples are represented by vertical bars. 


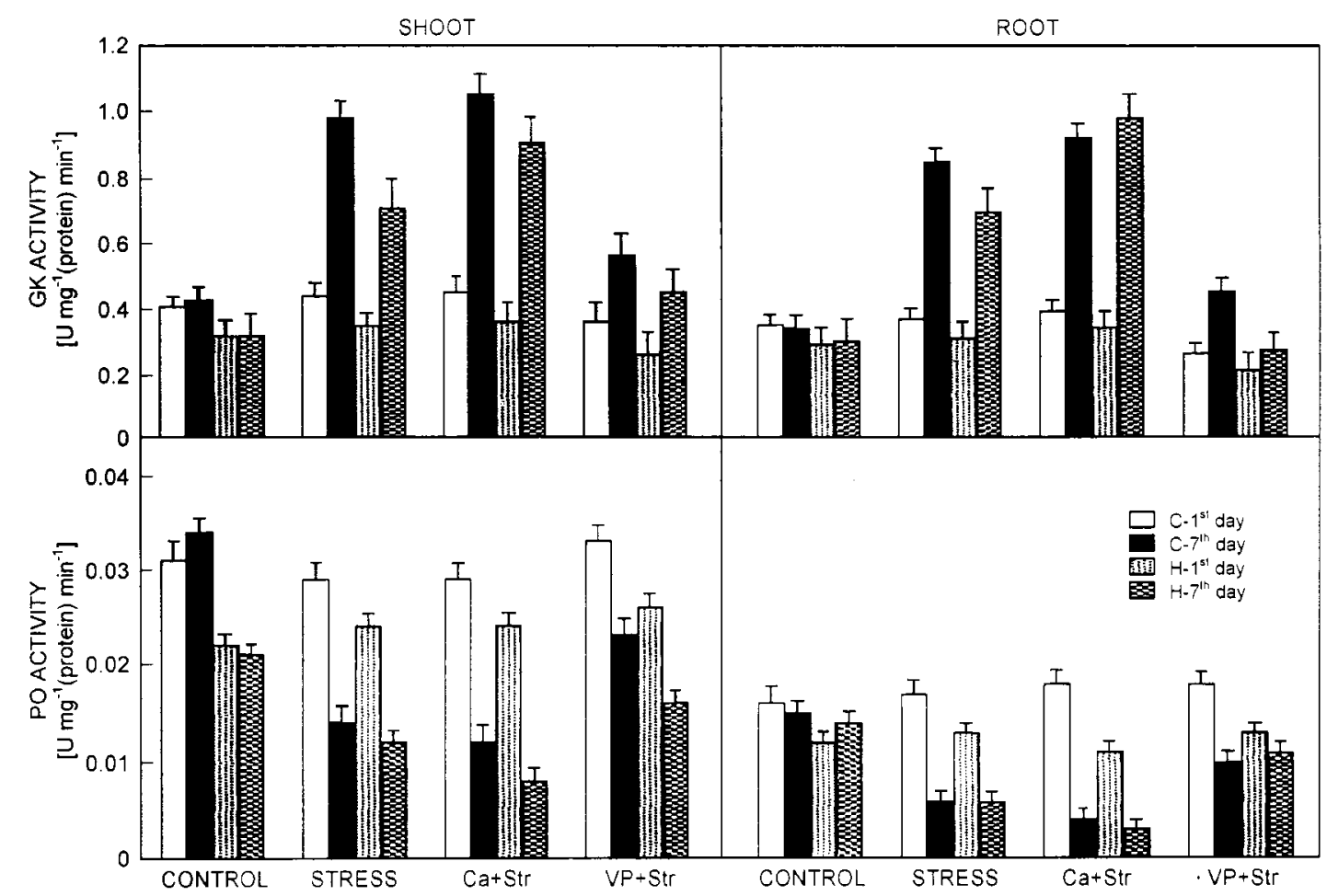

Fig. 2. Effect of water stress. $1 \mathrm{mM}$ calcium chloride (Ca) and $0.5 \mathrm{mM}$ calcium channel blocker verapamil (VP) on activity of $\gamma$-glutamyl kinase and proline oxidase in shoots and roots.

\section{Discussion}

The present findings indicated that stress sensitivity of the contrasting wheat genotypes might lie in variation in accumulation of osmolytes and hence osmoregulation mechanisms, an observation reported earlier in some other crops (Morgan et al. 1991, Ghoulam et al. 2002) including wheat (Morgan 1992).

Elevation of Pro was linked to higher activity of its biosynthetic enzyme, $\gamma$-glutamyl kinase (GK) and reduction in activity of catabolic enzyme, proline oxidase (PO). As reported before, the accumulation of proline in stressed plants is regulated both by activation of its biosynthesis and inactivation of its degradation (Yoshiba et al. 1997, Hare et al. 1999). The tolerant genotype showed significantly higher content and rate of Pro accumulation relative to the susceptible genotype; the difference could be attributed to variation in regulation mechanisms of Pro metabolism. The tolerant genotype had higher activity of GK and às well as of PO than its counterpart, but the kinase activity appeared to override the PO activity thus maintaining higher Pro content in tolerant genotype. The susceptible genotype though had higher amount of glycine betaine (GB) than the tolerant genotype, the rate of its accumulation was almost similar in both the genotypes in shoots but slightly more in the roots of tolerant genotype. This indicated that despite having relatively low content of $\mathrm{GB}$, the tolerant genotype compensated itself with higher rate of its accumulation. The preferential accumulation of an osmolyte could also be an important factor in determining the stress sensitivity (Rathinasabapathi 2000). The stress tolerance could be linked to higher accumulation of osmolytes like Pro or GB as observed by Kavi Kishor et al. (1995) who could over-express Pro in tobacco by engineering P5CS to produce stress tolerant plants. Some recent attempts on metabolic engineering to over-express or introduce osmolytes like Pro, GB and trehalose also demonstrate that stress tolerance of the plants could be strongly dependent upon the presence or absence of a critical content of osmolyte in the plant (Huang et al. 2000). The shoots of the tolerant genotype maintained higher pressure potential under stress as indicated by higher water potential than the susceptible genotype and Pro and GB could be important determinants in this context. Better ability of the tolerant genotype to osmoregulate under stress was also reflected in its higher root and shoot growth. A strong positive correlation existed between Pro content and growth of roots $(r=0.95 ; P \leq 0.05)$ and shoots $(r=0.91 ; P \leq 0.05)$ of the tolerant genotype as compared to the susceptible genotype which showed more significant relationship of growth with GB content of roots $(r=0.93 ; P \leq 0.05)$ and shoots $(r=0.91 ; P \leq 0.05)$. 


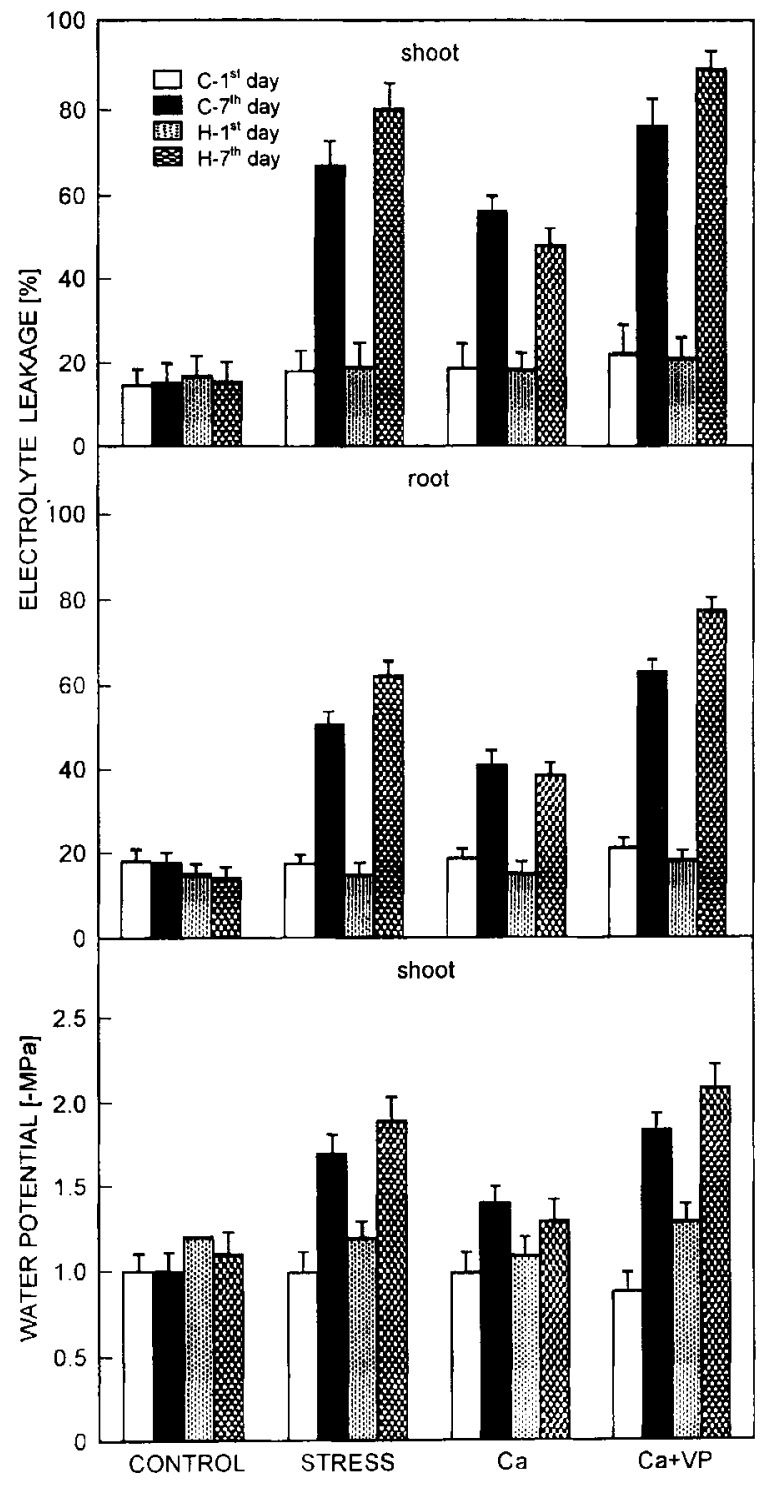

Fig. 3. Effect of water stress, $1 \mathrm{mM}$ calcium chloride (Ca) and $0.5 \mathrm{mM}$ calcium channel blocker, verapamil (VP) on electrolyte leakage and water potential.
It was apparent that the capacity to accumulate Pro and GB between shoots and roots was markedly different. It could be due to variation in their osmoregulation mechanisms or inherent control in production of these osmolytes. Though shoots showed higher content of solutes, their rate of accumulation was observed to be higher in roots. The rate of increase of osmolytes rather than their content per se may be more important (Hare and Cress 1997) for roots than shoots as they (roots) showed less damage due to stress as was evident from less electrolyte leakage, higher elongation rate and dry matter production under stress. Roots have been reported to be comparatively more tolerant to water deficit stress than shoots (Blum 1996) and variation in accumulation of osmolytes might govern this response to a considerable extent. Some other mechanisms may also determine the differential growth of roots and shoots under stress. For example, $\mathrm{ABA}$ accumulation in the roots due to water stress was found to be responsible for reducing shoot growth on one hand and sustaining root growth on the other hand (Sharp 2002).

It was observed in the present studies that $\mathrm{Ca}^{2+}$ affected the osmoregulation capacity by increasing the contents of Pro and GB, leading to higher water potential gradient and thereby improving the water uptake and growth under stress. Shah et al. (1990) reported increase in Pro content of alfalfa cultures in the presence of exogenous $\mathrm{Ca}^{2+}$. In Phaseolus vulgaris plants experiencing osmotic stress in the presence of $\mathrm{Ca}^{2+}$ in the growth medium, a decrease in initial loss of water in the roots was reported (Ortiz et al. 1994) which was attributed to regulation of content of organic metabolites related to osmotic adjustment by $\mathrm{Ca}^{2+}$. As observed in the present study, $\mathrm{Ca}^{2+}$ raised the content of Pro by stimulating the activity of GK and depressing the activity of PO. Inhibitor studies supported the involvement of $\mathrm{Ca}^{2+}$ in affecting Pro and $\mathrm{GB}$ accumulation. $\mathrm{Ca}^{2+}$ has also been earlier implicated in maintenance of membrane integrity, reduction of oxidative damage by elevating the content of the antioxidants or increasing the activity of

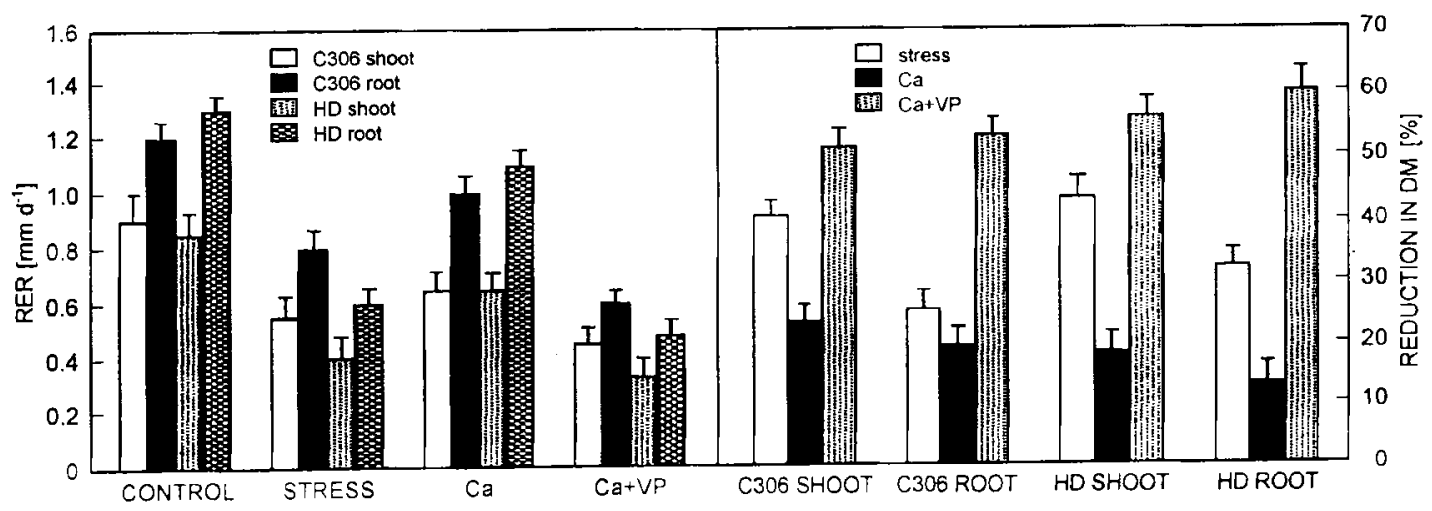

Fig. 4. Effect of water stress, $1 \mathrm{mM}$ calcium chloride $(\mathrm{Ca})$ and $0.5 \mathrm{mM}$ calcium channel blocker, verapamil (VP) on relative elongation rate (RER) and dry matter accumulation in shoots and roots of C306 and HD2329 (HD) wheat genotypes. 
oxidative enzymes (Ming et al. 1998, Larkindale and Knight 2002, Nayyar and Kaushal 2002).

The two genotypes differed in their response to $\mathrm{Ca}^{2+}$ application under stress conditions as was evident from accumulation of osmolytes and growth of root and shoots under stress. Though $\mathrm{Ca}^{2+}$ could increase the amount of osmolytes and growth in both the genotypes, the susceptible genotype was particularly more stimulated. This indicates that $\mathrm{Ca}^{2+}$ expression in both the genotypes may differ and the susceptible genotype may be unable to fully express $\mathrm{Ca}^{2-}$ due to variation in some of the key

\section{References}

Arazi, T., Sunkar, R., Kaplan, B.: A tobacco plasma membrane calmodulin-binding transporter confers $\mathrm{Ni}^{2+}$ tolerance and $\mathrm{Pb}^{2-}$ hypersensitivity in transgenic plants. - Plant J. 20: 171 182. 1999

Bates, L.S., Waldren, R.P., Teare, I.D.: Rapid determination of free proline for water stress studies. - Plant Soil 39: 205217,1973

Blum, A.: Crop responses to drought and the interpretation of adaptation. - Plant Growth Regul. 20: 135-148, 1996.

Delauney, A.J., Verma, D.P.S.: Proline biosynthesis and osmoregulation in plants. - Plant J. 4: 215-222, 1993.

DeRonde, J.A.. Spreeth, M.H., Cress, W.A.: Effect of antisense pyrroline-5-carboxylate reductase transgenic soybean plants subjected to osmotic and drought stress. - Plant Growth Regul. 32: 13-26. 2000.

Ghoulam. C.. Foursy, A.. Fares, K.: Effects of salt stress on growth, inorganic ions and proline accumulation in relation to osmotic adjustment in five sugar beet cultivars. - Environ. exp. Bot. 47: 39-50. 2002.

Grieve. C.M., Grattan. S.R.: Rapid assay for determination of water soluble quaternary ammonium compounds. - Plant Soil 70: 303-307. 1983.

Hare. P.D. Cress. W.A.: Metabolic implications of stressinduced proline accumulation in plants. - Plant Growth Regul. 21: 79-1025. 1997.

Hare. P.D., Cress, W.A., Van Staden, J.: Proline synthesis and degradation: a model system for elucidating stress-related signal transduction - J. exp. Bot. 50: 413-434, 1999.

Hayzer. B.J.. Leisinger, T.H.: The gene enzyme relationships of proline biosynthesis in Escherichia coli. - J. gen. Microbiol. 118: $287-293,1980$

Huang. A.H.C., Cavalieri, A.: Proline oxidase and water stress induced proline accumulation in spinach leaves. - Plant Physiol. 63: 531-535. 1979.

Huang, J., Hirii. R., Adam, L., Rozwadowski, K.L., Hammerlindl, I.K.. Keller, W.A., Selvaraj, G.: Genetic engineering of glycinebetaine production toward enhancing stress tolerance in plants: metabolic limitations. - Plant Physiol. 122: 747-756, 2000.

Kavi Kishor. P.B., Hong, Z., Miao, G., Hu, C., Verma, D.P.S.: Overexpression of $\Delta^{\prime}$-pyrroline-5-carboxylate synthetase increases proline overproduction and confers osmotolerance in transgenic plants. - Plant Physiol. 108: 1387-1394, 1995.

Knight. H., Knight, M.R: Abiotic stress signaling pathways: specificity and cross talk. - Trends Plant Sci. 6: 262-267, 2001. component(s) of $\mathrm{Ca}^{2+}$ functioning (e.g., release mechanisms, channels or sensors related to $\mathrm{Ca}^{2+}$ ) which may increase its sensitivity to exogenous calcium application. It will be worthwhile to examine endogenous $\mathrm{Ca}^{2+}$ expression and its signaling mechanisms in such contrasting genotypes to precisely relate the variation in their stress sensitivity to $\mathrm{Ca}^{2+}$ functioning. Recently it has been reported that $\mathrm{Ca}^{2+}$ expression can be engineered by controlling one of its signaling components to induce stress tolerance (Arazi et al. 1999).

Knight, H., Trewavas, A.J., Knight, M.R.: Calcium signaling in Arabidopsis thaliana responding to drought and salinity. Plant J. 12: 91 1-922, 1997.

Krall, J.P., Edwards, G.E., Andreo, C.S.: Protection of pyruvate, $\mathrm{Pi}$ dikinase from maize against cold lability by compatible solutes. - Plant Physiol. 80: 280-285, 1989.

Larkindale, J., Knight, M.R.: Protection against heat stressinduced oxidative damage in Arabidopsis involves calcium, abscisic acid, ethylene, and salicylic acid. - Plant Physiol. 128: $682-695,2002$.

Lutts, S., Kinet, J.M., Bouharmont, J.: NaCl-indiced senescence in leaves of rice (Oryza sativa L.) cultivars differing in salinity resistance. - Ann. Bot. 78: 389-398, 1996.

McNeil, S.D., Nuccio, M.L., Hanson, A.D.: Betaines and related osmoprotectants. Targets for metabolic engineering of stress resistance. - Plant Physiol. 120: 945-949, 1999.

Ming, G., Li, Y.-J., Chen, S.-Z.: Abscisic acid-induced thermotolerance in maize seedlings is mediated by calcium and associated with antioxidant systems. - J. Plant Physiol. 153: 488-496, 1998.

Morgan, J.M.: Osmotic components and properties associated with genotypic differences in osmoregulation in wheat. Aust. J. Plant Physiol. 19: 67-76, 1992.

Morgan, J.M., Rodriguez Maribona, B., Knight, E.J.: Adaptation to water-deficit in chickpea breeding lines by osmoregulation-relationship to grain yields in the field. Field Crops Res. 27: 61-70, 1991.

Murata, N., Mohanty, P.S., Hayashi, H., Papageorgiou, G.C.: Glycinebetaine stabilizes the association of extrinsic proteins with the photosynthetic oxygen-evolving complex. - FEBS Lett. 296: 187-189, 1992.

Nayyar, H., Kaushal, S.K.: Chilling induced oxidative stress in germinating wheat grains as affected by water stress and calcium. - Biol. Plant. 45: 601-604, 2002.

Ortiz, A., Martinez, V., Cerda, A.: Effects of osmotic shock and calcium on growth and solute composition of Phaseolus vulgaris plants. - Physiol. Plant. 91: 468-476, 1994.

Papageorgiou, G.C., Murarata, N.: The unusually strong stabilizing effects of glycinebetaine on the structure and function in the oxygen-evolving photosystem II complex. Photosynth. Res. 44: 243-252, 1995.

Rathinasabapathi, B.: Metabolic engineering for stress tolerance: Installing osmoprotectant synthesis pathways. Ann. Bot. 86: 709-716, 2000.

Rhodes, D., Hanson, A.D.: Quaternary ammonium and tertiary sulfonium compounds in higher plants. - Annu. Rev. Plant 
Physiol. mol. Biol. 44: 357-388, 1993.

Shah, S.H., Wainwright, S.J., Merrett, M.J.: The interaction of sodium and calcium chlorides and light on growth, potassium nutrition, and proline accumulation in callus cultures of Medicago sativa L. - New Phytol. 116: 37-45, 1990.

Sharp, R.E.: Interaction with ethylene: changing views on the role of abscisic acid in root and shoot growth responses to water stress. - Plant Cell Environ. 25: 211-222, 2002.

Trotel-Aziz, P., Niogret, M.F, Larher, F.: Proline level is partly under the control of abscisic acid in canola leaf discs during recovery from hyper-osmotic stress. - Physiol. Plant. 110:
376-383, 2000.

Yang, C.W., Wang, J.W., Kao, C.H.: The relation between accumulation of abscisic acid and proline in detached rice leaves. - Biol. Plant. 43: 301- 304, 2000.

Yoshiba, Y., Kiyosu, T., Nakashima, K., Yamaguchi-Shinozaki, K., Shinozaki, K.: Regulation of levels of proline as an osmolyte under plant stress. - Plant Cell Physiol. 38: 1095$1102,1997$.

Zhao, Y., Aspinall, D., Paleg, L.G.: Protection of membrane integrity in Medicago sativa L. by glycinebetaine against the effects of freezing. - J. Plant Physiol. 140: 541-543, 1992. 